
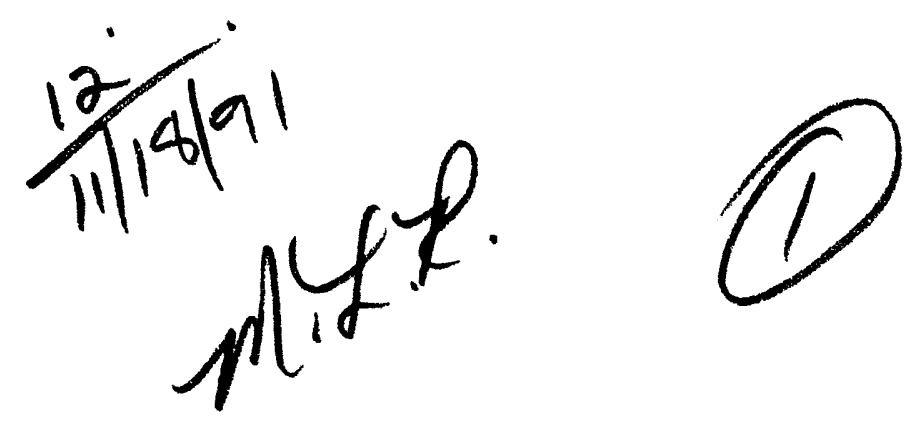

UCRL-ID--108581

DE92 002941

\title{
Casting Process Modeling Using CAST2D The Part Mold Interface
}

\author{
Arthur B. Shapiro
}

October 1991

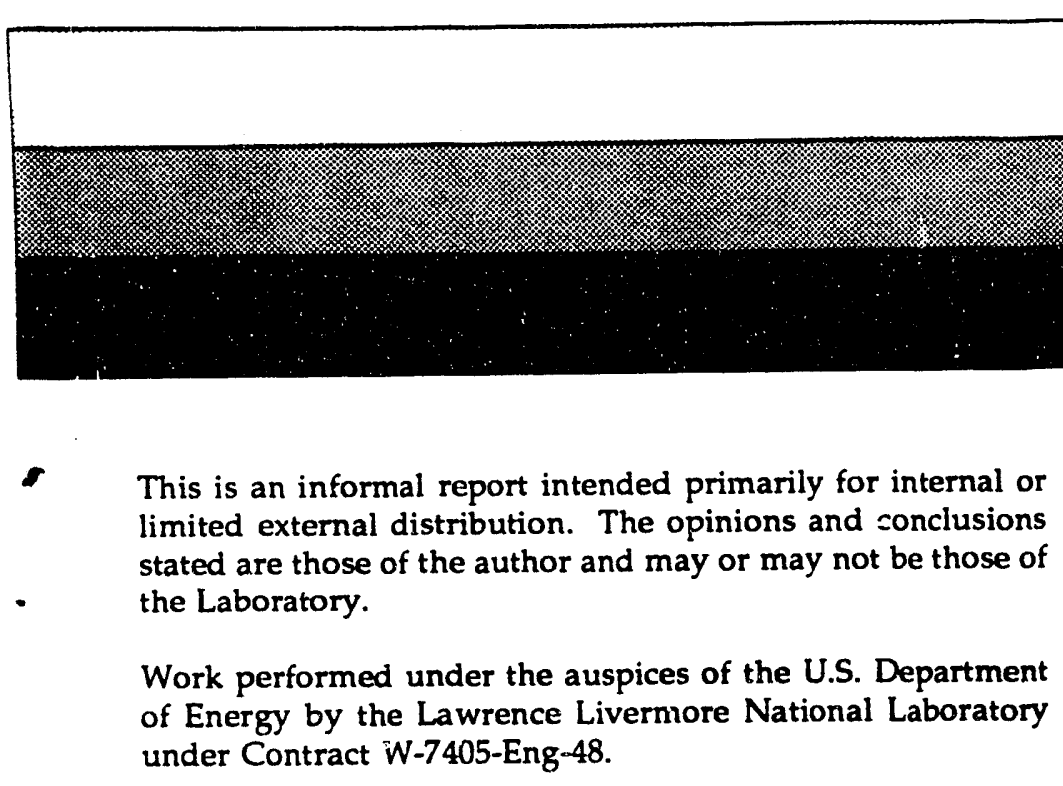




\section{DISCLAIMER}

This document was prepared as an acccount of work sponsored by an agency of the United States Government. Neither the United States Government nor the University of California nor any of their employees, makes any warranty, express or implied, or assumes any legal liability or responsibility for the accuracy, completeness, or usefulness of any information, apparatus, product, or process disclosed, or represents that its use would not infringe privately own rights. Reference herein to any specific commercial products, process, or service by trade name, trademark, manufacturer, or otherwise, does not necessarily constitute or imply it, endorsement, recommendation, or favoring by the United States Government or the University of California. The views and opinions of authors expressed herein do not necessiarily state or reflect those of the United States Government or the University of California, and shall not be used for advertising or product endorsement purposes.

This report has been reproduced directly from the best available copy.

Available to DOE and DOE contractors from the Office of Scientific and Technical Information

$$
\text { P.O. Box 62, Oak Ridge, TN } 37831
$$

Prices available from (615) 576-8401, FTS 626-8401

Available to the public from the National Technical Information Service

U.S. Department of Commerce 5285 Port Royal Rd.

Springfield, VA 22161 


\title{
Casting Process Modeling Using CAST2D
}

\section{The Part-Mold Interface}

\author{
Arthur B. Shapiro
}

October 1991

Correctly modeling the physics across the part-mold interface is crucial in predicting the quality of a cast part. Most metals undergo a volume change on solidification (e.g., aluminum $-6.6 \%$ ) and shrinkage on cooling. As the cast metal shrinks, it pulls away from the mold wall creating a gap. This gap effects the thermal contact resistance between the part and mold. The thermal contact resistance increases as the gap widens. This directly effects the cooling rate and ultimately the final cast shape, stress state, and quality of the cast part.

CAST2D [1] is a coupled thermal-stress finite element computer code for casting process modeling. This code can be used to predict the final shape and stress state of cast parts. CAST2D couples the heat transfer code TOPAZ2D [2] and solid mechanics code NIKE2D [3]. CAST2D has the following features in addition to all the features contained in the TOPAZ2D and NIKE2D codes:

- A general purpose thermal-mechanical interface algorithm (i.e., slideline) that calculates the thermal contact resistance across the part-mold interface as a function of interface pressure and gap opening.

- A new phase change algorithm, the delta function method, that is a robust method for materials undergoing isothermal phase change.

- A constitutive model that transitions between fluid behavior and solid behavior, and accounts for material volume change on phase change.

- A modified plot file data base that allows plotting of thermal variables (e.g., temperature, heat flux) on the deformed geometry.

CAST2D is a code in development. The first three features mentioned above are current research areas. The numerical implementation of these features will be refined over the next year and validated against experimental data. This report presents the status of item 1 , a general purpose thermal-mechanical interface algorithm. 


\subsection{Background}

John Hallquist developed general mechanical slideline algorithms in his development of the NIKE2D code between 1978-1988. His treatment included tied, sliding only, sliding with voids, sliding with friction and single surface contact slidelines. Arthur Shapiro developed a general thermal slideline algorithm in his development of the TOPAZ2D code. In the CAST2D code, the slideline features of NIKE2D and TOPAZ2D are combined into a general purpose thermal-mechanical slideline. This slide line accounts for the changing thermal contact resistance as a function of gap size. Heat transfer by conduction and radiation across the gap are included.

\subsection{Theory}

The TOPAZ2D [2] and NIKE2D [3] user manuals should be consulted for a information on the general theory behind the mechanical and thermal slidelines, respectively. The coupled thermal-mechanical slideline treatment is as follows.

1) NIKE2D calculates the slideline connectivity (i.e., nodes and segments that are in contact) based on the current geometry and passes this information to TOPAZ2D.

2) TOPAZ2D calculates the contact resistance to be used in the thermal calculations. If the NIKE2D slideline data indicates interface segment penetration by a node, then perfect thermal contact is assumed. If a gap is detected, then the contributions to the thermal contact resistance due to conduction

$$
R_{c}=\frac{l}{k}
$$

and radiation

$$
R_{r}=\frac{\left(T_{1}-T_{2}\right)}{\sigma \varepsilon\left(T_{1}^{4}-T_{2}^{4}\right)}
$$

are calculated. $\mathbf{k}$ is the thermal conductivity of the gas in the gap, $l$ is the gap thickness, $\sigma$ is the Stefan Boltzmann constant and $\varepsilon$ is the surface emissivity. The overall resistance due to these two components acting in parallel is

$$
R=\frac{R_{c} R_{r}}{R_{c}+R_{r}}
$$




\subsection{Example}

Censider liquid aluminum poured into a steel cup as depicted in figure 1 . The initial temperature of the aluminum and steel is $950 \mathrm{~K}$. The outer surface of the steel cup and top free surface of the aluminum lose heat by convection and radiation to the environment. The aluminum undergoes liquid to solid phase change at $933 \mathrm{~K}$ with a volume change of $-6.6 \%$. Shown in figures $2 \mathrm{a}$ is the final cast shape of the aluminum part when interface movement between part and mold is restricted. The volume change due to the aluminum shows up as a depression in the top aluminum surface. Figure $2 b$ shows the final cast shape when an interface treatment allowing motion between the part and mold is invoked.

FIGURE 1. The mold for the example problem consists of a steel cup in which liquid aluminum is poured.

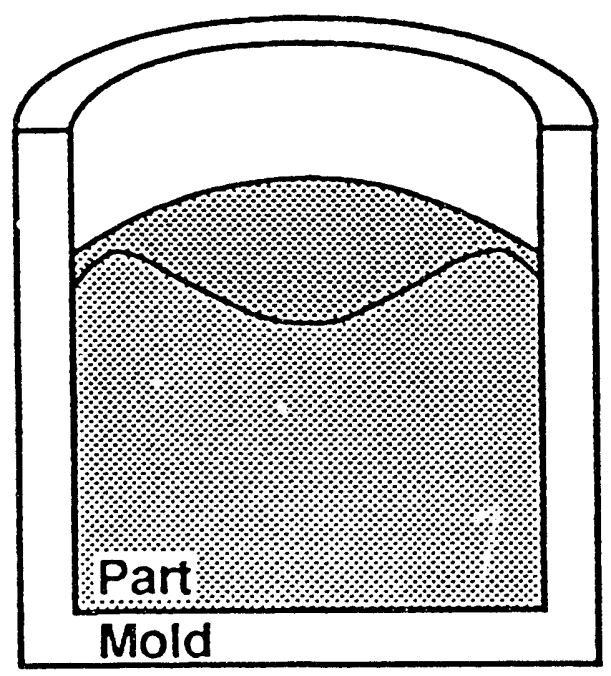


FIGURE 2. A different final cast shape results when allowing motion (i.e., slideline) between the cast part and mold.

2a: without slideline

$\mathbf{z}$

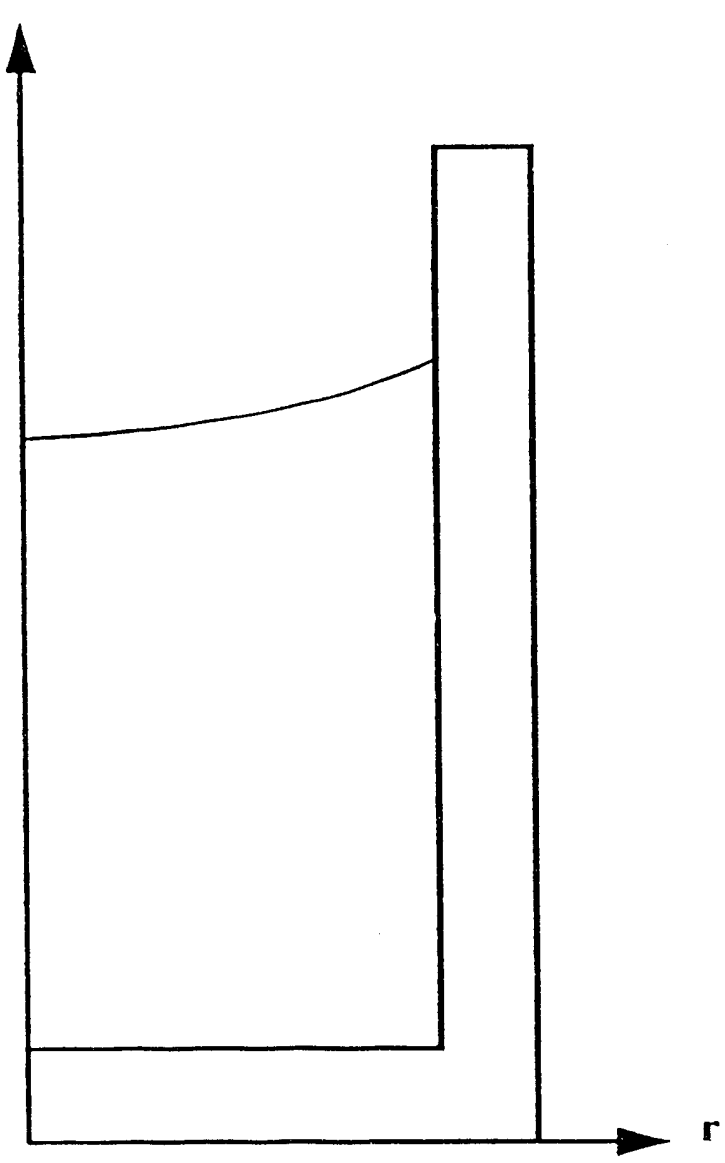

2b: with slideline

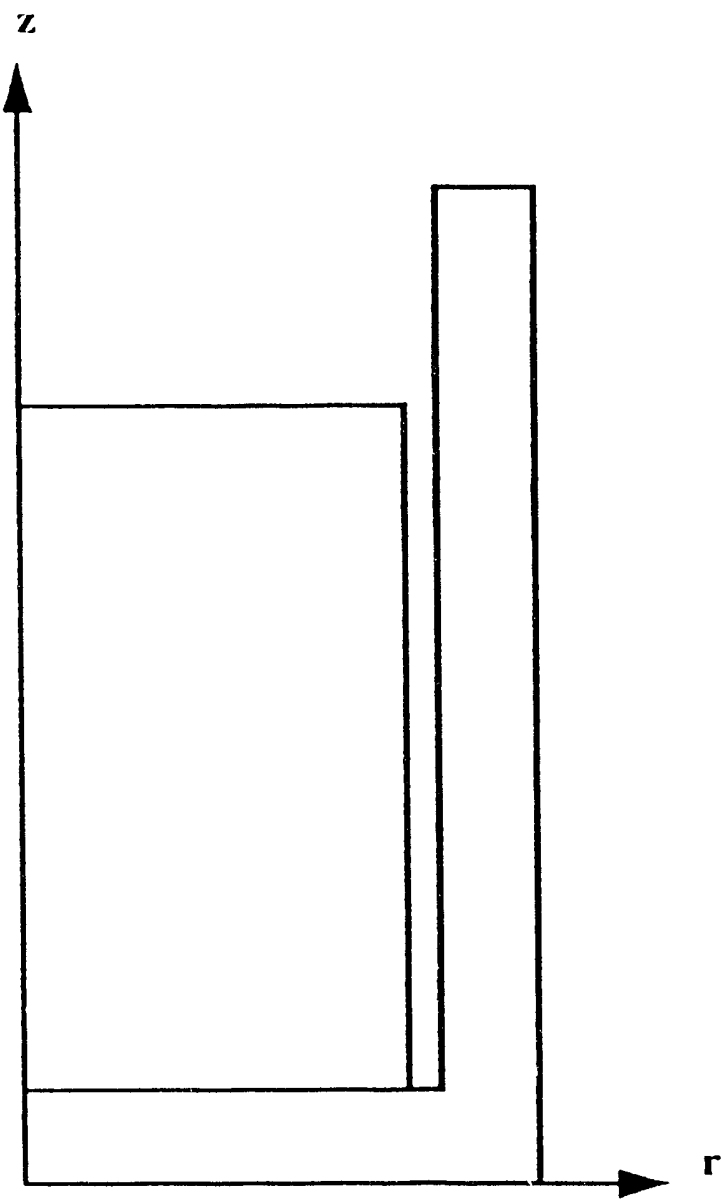

Figure 3 shows a sequence of flux plots at various times during the cool down. In figure $3 a$ at early time, their is very good contact across the entire mold-part interface. The flux vectors (i.e., heat flow path) are seen to go from the hot aluminum into the steel can. The maximum cooling rate is at the top right portion of the aluminum part as indicated by the size of the flux vectors. At later time as depicted in figure $3 \mathrm{~b}$, a gap has started to open at this location due to volume shrinkage on solidification. Note that the direction of the heat flux vectors have changed seeking the path of least resistance to heat flow. When a gap exists along the entire vertical part-mold interface as shown figure $3 \mathrm{c}$, the heat flow path is out the top and bottom aluminum surfaces. 
FIGURE 3. The heat flow path across the vertical part-mold interface changes as the part shrinks away from the mold on solidification.

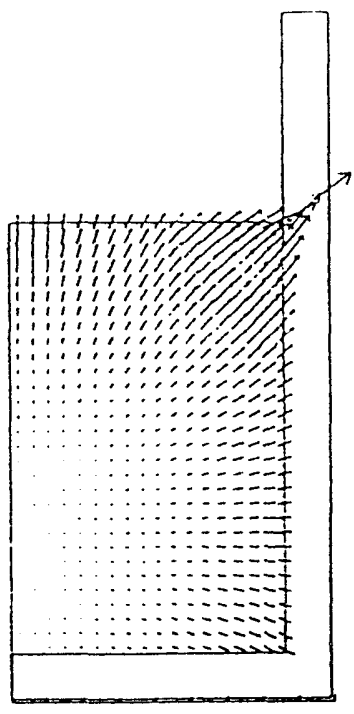

3a: full contact

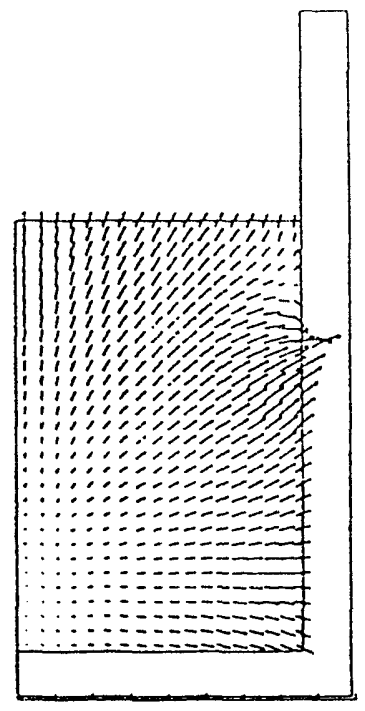

3b: partial contaci

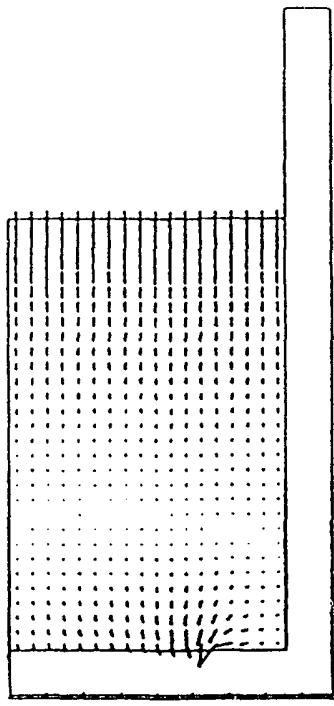

3c: no contact

\subsection{References}

1 A.B. Shapiro, "CAST2D - A Finite Element Computer Code for Casting Process Modeling", University of California, Lawrence Livermore National Laboratory, UCRL-MA-108598, October 1991.

2 A. B. Shapiro, "TOPAZ2D Heat Transfer Code Users Manual and Thermal Property Data Base", University of Califomia, Lawrence Livermore National Laboratory, Rept UCRL-ID-104558, May 1990.

3 J. O. Hallquist, "NIKE2D - A Vectorized Implicit, Finite Deformation, Finite Element Code for Analyzing the Static and Dynamic Response of 2-D Solids with Interactive Rezoning and Graphics", University of California, Lawrence Livermore National Laboratory, Rept UCID-19677, 1986. 

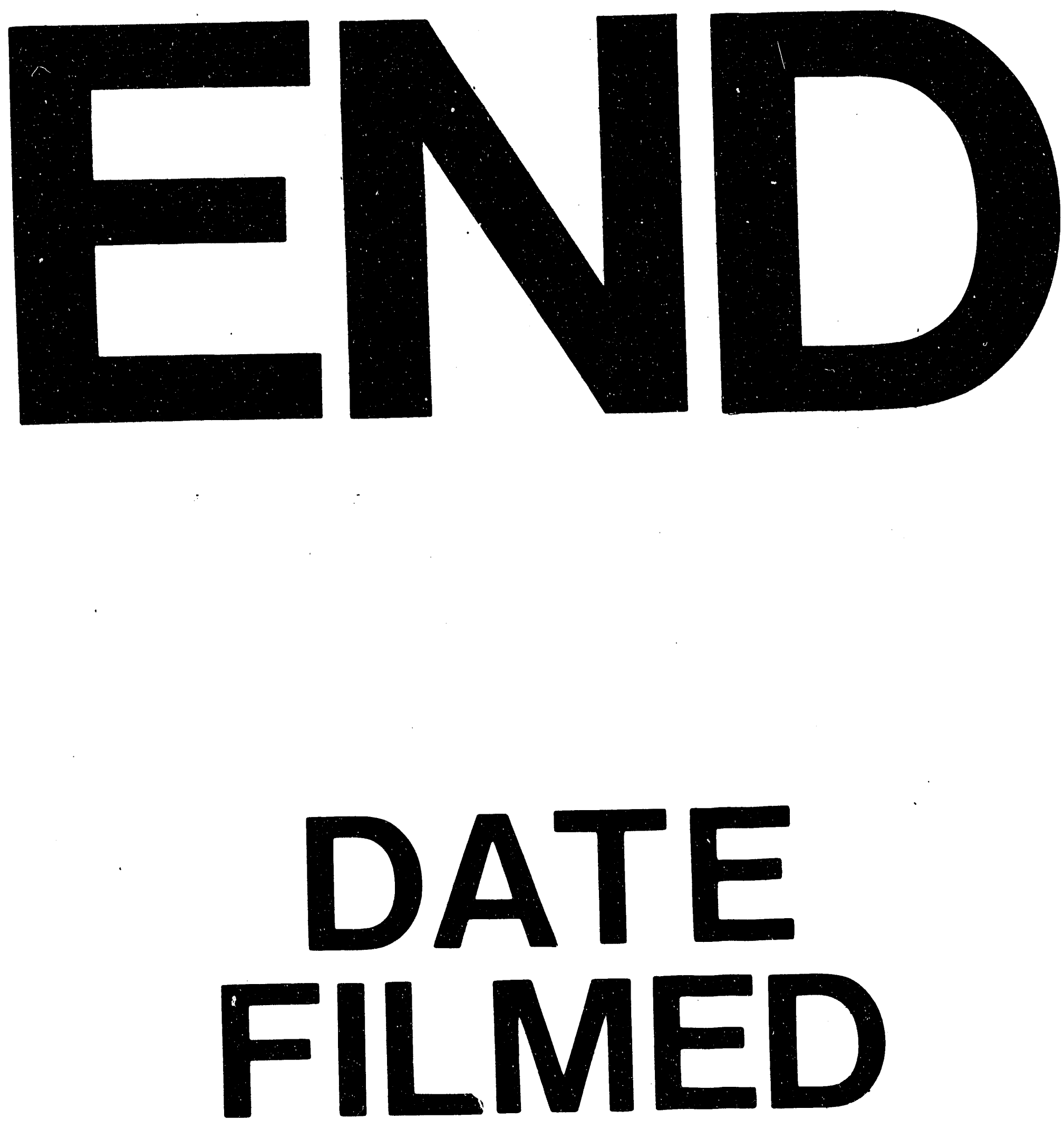

I

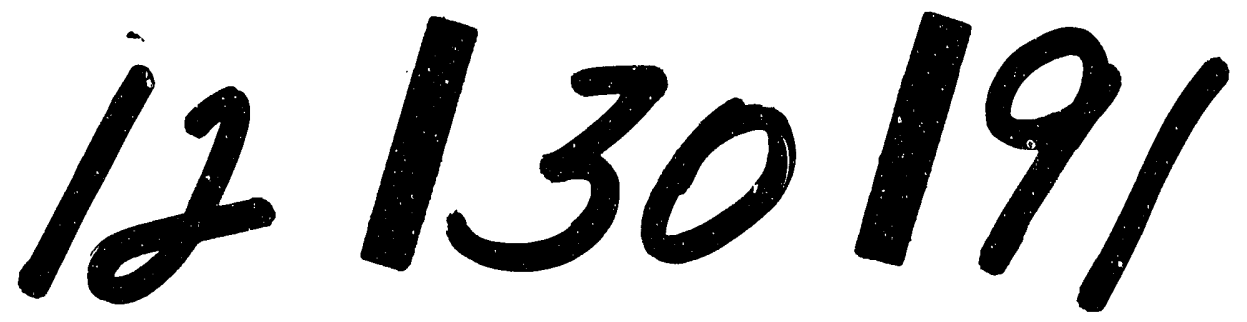


